\title{
Evaluation Model in Decision Analysis: Bipolar Approach *
}

\author{
Ayeley P. TCHANGANI ${ }^{1}$, Yasmina BOUZAROUR-AMOKRANE ${ }^{2}$, \\ François PÉRÈS ${ }^{3}$ \\ ${ }^{1}$ Université Toulouse III - IUT de Tarbes \\ 1 rue Lautréamont, 65016 Tarbes, France \\ ${ }^{2}$ Université Toulouse III - Paul Sabatier \\ 118 route de Narbonne, 31062 Toulouse, France \\ ${ }^{3}$ École Nationale d'Ingénieurs de Tarbes \\ 47 Avenue d'Azereix, 65016 Tarbes, France \\ e-mail:ayeley.tchangani@iut-tarbes.fr,yasmina.bouzarour@enit.fr,francois.peres@enit.fr
}

Received: October 2011; accepted: February 2012

\begin{abstract}
Three main approaches presently dominate preferences derivation or evaluation process in decision analysis (selecting, ranking or sorting options, alternatives, actions or decisions): value type approach (a value function or an utility measure is derived for each alternative to represent its adequacy with decision goal); outranking methods (a pair comparison of alternatives are carried up under each attribute or criteria to derive a pre-order on the alternatives set); and decision rules approach (a set of decision rules are derived by a learning process from a decision table with possible missing data). All these approaches suppose to have a single decision objective to satisfy and all alternatives characterized by a common set of attributes or criteria. In this paper we adopt an approach that highlights bipolar nature of attributes with regards to objectives that we consider to be inherent to any decision analysis problem. We, therefore, introduce supporting and rejecting notions to describ attributes and objectives relationships leading to an evaluation model in terms of two measures or indices (selectability and rejectability) for each alternative in the framework of satisficing game theory. Supporting or rejecting degree of an attribute with regard to an objective is assessed using known techniques such as analytic hierarchy process (AHP). This model allows alternatives to be characterized by heteregeneous attributes and incomparability between alternatives in terms of Pareto-equilibria.
\end{abstract}

Keywords: evaluation model, multi-objectives, multi-attributes, analytic hierarchy process, satisficing games.

\section{Introduction and Statement of the Problem}

Decision analysis, that is selecting, ranking, classifying or sorting (clustering) alternatives, options, actions or decisions (generically referred to as alternatives in this paper), is probably the main activity of any human being. Some decisions are routinely and do not need sophisticated algorithms to support decision process whereas other decisions need

*Preliminary version of this paper was presented at ROADEF 2011 as a communication. 
more or less complex processes to reach a final decision. These complex decisions share some features such as: multiplicity of objectives to satisfy, multiplicity of attributes or criteria that characterize alternatives, uncertainty, multiplicity of actors, and so on. For these decision situations there is a need to have a procedure or an evaluation model. Two great paradigms are considered in decision analysis literature: multi-criteria or multi-attributes decision making and multi-objectives decision making, see for instance (Antucheviciene et al., 2011; Bouyssou et al., 2000; Roy and Bouyssou, 1993; Steuer, 1986; Vincke, 1989; Nemura and Klementavicius, 2008; Turskis and Zavadskas, 2010), with sometime a certain confusion between these paradigms. To clarify the position adopted in this paper, let us consider following definition.

DEFINITION 1. An objective in a decision analysis problem is something decision maker(s) care about, want to achieve, want to optimize, want to reach, etc. whereas an attribute or a criterion is a feature of an alternative that is used to evaluate this alternative with regard to pursued objectives.

Given previous definition, it becomes obvious that a decision analysis problem can be both multi-criteria/multi-attributes and multi-objectives and this is assumed in this paper. Decision analysis is, in general, a process with many steps such as formulating decision goal or objectives, identifying attributes that characterize potential alternatives that can respond to the decision goal and making recommendation regarding these alternatives given the decision goal. The final recommendation step in a decision process can be reduced to three main processes: choosing (this is a relative evaluation that finds a subset, possibly reduced to a singleton, of alternatives that satisfy the decision goal), ranking (relative evaluation that ranks alternatives from the best to the worst with regard to the decision goal) or sorting (an absolute evaluation that sorts alternatives according to a prescribed norm regarding the decision goal). The construction of an evaluation model, often carried by an expert known in the literature as the analyst (Bouyssou et al., 2000) is then an important step in the decision process; this step is the main purpose of this paper. Indeed, we consider that the upstream processes have been considered and we are in possession of the set of alternatives, the consequences tree, attributes measures and our duty is to construct an evaluation model, thus we act as an analyst for the final recommendation. The purpose of this paper is to derive an evaluation model for mainly selecting and/or ranking process in order to achieve multiple objectives; this decision making context is summarized by the following definition.

DEFINITION 2. The decision making problem considered here consists in 3-uples $\langle\mathcal{U}, \mathcal{A}, \mathcal{O}\rangle$ where:

- $\mathcal{U}$ is a discrete set of $n$ alternatives

$$
\mathcal{U}=\left\{u_{1}, u_{2}, \ldots, u_{n}\right\}
$$


- $\mathcal{A}$ is a discrete set of $m$ attributes or criteria

$$
\mathcal{A}=\left\{a_{1}, a_{2}, \ldots, a_{m}\right\}
$$

- $\mathcal{O}$ is a discrete set of $k$ objectives to satisfy that resume the overall decision goal

$$
\mathcal{O}=\left\{o_{1}, o_{2}, \ldots, o_{k}\right\}
$$

A decision making problem as defined previously can represent practical situations in many domains such as management, engineering, economics, politics (see for instance Geldermann and Rentz (2003) for an application in e-democracy) etc.; interested readers can consults following publications (Antucheviciene et al., 2011; Bouyssou et al., 2000; Nemura and Klementavicius, 2008; Roy and Bouyssou, 1993; Steuer, 1986; Vincke, 1989; Tchangani, 2009; Turskis and Zavadskas, 2010; Kanapeckiene et al., 2011) and references therein for some real world applications. Applications may also be found in society protection and emergency management such as decision making related to protection against fire (Vaidogas and Sakenaite, 2011) or in human-machine interface design (Kabassi et al., 2005); multicriteria classification problems as decision making problems are encountered in many domains such as finance (Doumpos et al., 2001), among others. The context considered here is different from the case where one want to form a portfolio of alternatives such as in projects management, see for instance Liesio et al. $(2007,2008)$, because we do not consider relationships between alternatives.

Classically, three main approaches have dominated evaluation process in decision analysis: value type approach (a value function or an utility measure is derived for each alternative to represent its adequacy with decision goal); outranking methods (a pair comparison of alternatives are carried up under each attribute or criteria to derive a pre-order on the alternatives set); and decision rules approach (a set of decision rules are derived from a decision table with possible missing data). All these approaches suppose to have a single objective to satisfy and a common attributes set for alternatives. These approaches are briefly described below.

- Value type approach: roughly speaking these techniques consider a numerical function $\pi$ (known as value or utility function) defined on the alternatives set $\mathcal{U}$ such that

$$
\pi(u) \geqslant \pi(v) \quad \Leftrightarrow \quad u \succsim v, \quad u, v \in \mathcal{U},
$$

where " $u \succsim v$ " stands for " $u$ is at least as good, with regard to decision goal, as $v$ " leading to an order on $\mathcal{U}$. The evaluation modeling process then consists in building such a function based on attributes measures and decision makers preference (obtained in general by answering some particular questions of the analyst); there are many techniques employed in the literature for constructing such a function where a number of them suppose a particular form for $\pi$ such as an expected utility form or an additive value function (interested reader may consult (Bouyssou et al., 
2000; Roy and Bouyssou, 1993; Jacquet and Sisko,1982; Steuer, 1986; Vincke, $1989)$ and references therein and AHP approach (Saaty, 1980) and its variation to take into account particular relationships between components of decision process (Basak, 2011).

- Outranking methods: a pair comparison of alternatives is carried up under each attribute or criteria to derive a pre-order on the alternatives set $\mathcal{U}$ allowing incomparability and/or intransitivity; methods such as ELECTRE procedures and PROMETHEE techniques (Bouyssou et al., 2000; Roy and Bouyssou, 1993; Vincke, 1989) belong to this category.

- Decision rules approach: a set of decision rules are derived by a learning process from a known decision table with possibly incomplete data (Geco et al., 2001).

To take into account some particular aspects of decision making process such as sequentiality or fuzziness of data, researchers are developing methods to deal with these issues, see for instance Ouerdane et al. (2011) for argumentation approach and Ramik and Perzina (2010) for fuzzy multicriteria decision problems. Some effort is also paid to the estimation of judgements or quantitative and subjective criteria weighting process (Monat, 2009).

In this paper we adopt an approach that highlights the bipolarity of attributes with regards to objectives that we consider to be inherent to any decision analysis problem. We are motivated by the fact that cognitive psychologists have observed for long time that human, often, evaluate alternatives by considering separately their positive aspects and their negative aspects; that is on a bipolar basis, see for instance Caciopo and Bernston (1994) and Osgood et al. (1957); this view is also common in computer science for information representation (Dubois and Fargier, 2006). To this end, we introduce supporting and rejecting notions (Tchangani, 2010) that relate attributes to objectives leading to an evaluation model in terms of two measures or indices (selectability and rejectability) for each alternative in the framework of satisficing game theory (Stirling, 2003). These notions permit to partition criteria or attributes set into three subsets given an objective: attributes that support this objective, attributes that reject this objective and attributes that are neutral with regard to this objective; of course only supporting and rejecting attributes are interesting for evaluation process. Supporting and rejecting degrees of an attribute with regard to an objective are assessed using known techniques such as analytic hierarchy process (AHP). In fact any method, such as performance value analysis (Gurumurthy and Kodali, 2007), that could assign a measure to an attribute with regard to a pair of objective and alternative can be used; here we choose to use AHP approach because of its ability to deal with hierarchy (which permits to decompose attributes from more general statements to more measurable or comparable attributes) and intangible variables. This model allows alternatives to be characterized by heterogeneous attributes and incomparability between alternatives in terms of Pareto-equilibria. Indeed, decision making situations where alternatives are characterized by attributes of different nature are pervasive in real world applications. One may think about a government evaluating projects that belong to different domains such health, infrastructures, social, economics with the main objective to enhance a country developing process or an enterprise planning to invests in projects 
of different nature. In these situations, though attributes characterizing projects may be completely different, the important thing is their adequacy with regards to the pursued objectives, so that the alternative projects can be ultimately compared on the same basis (decision maker desires).

The remainder of this paper is organized as follows: in the Section 2, modelling and assessment of supporting and rejecting relationships between attributes and objectives is considered through analytic hierarchy process (AHP); Section 3 is devoted to evaluation and recommendation procedures using satisficing game; Section 4 considers an illustrative application and Section 5 concludes the paper.

\section{Modelling and Assessment of Bipolar Relationships}

\subsection{Modelling}

As mentioned in previous section, cognitive psychologists noticed for long time that humans generally evaluate alternatives in decision process by comparing pros and cons of each alternative with regard to decision goal. Building on this observation, we define a supporting/rejecting relationship between attributes and objectives as given by the following definition.

DEFINITION 3. An objective $o_{j}$ is said to be supported (respect. rejected) by an attribute $a_{i}$ if and only if its variation is positively (respect. negatively) correlated with the variation of that attribute as illustrated by the following Fig. 1. Otherwise this attribute is said to be neutral with regard to that objective.
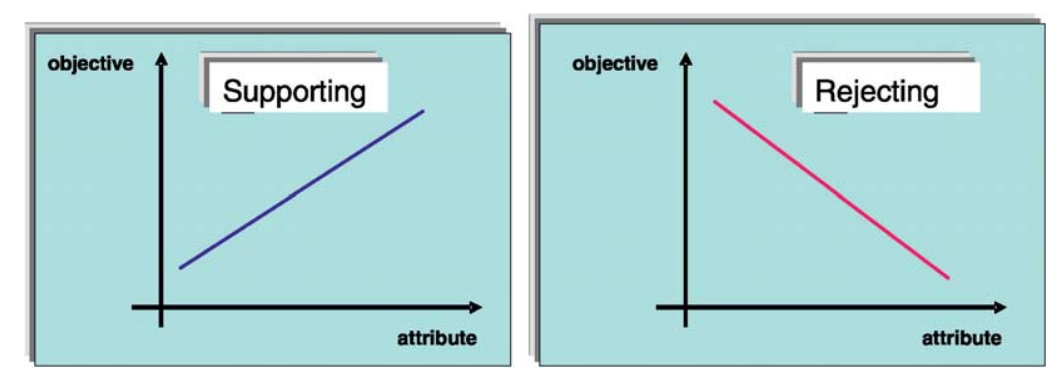

Fig. 1. Illustration of supporting and rejecting relationships between objectives and attributes.

Given a decision problem as defined in the previous section, for each objective $o_{j}$, the set of attributes $\mathcal{A}^{1}$ will be partitioned into $\mathcal{A}_{S}\left(o_{j}\right)$, the set of attributes that support objective $o_{j}, \mathcal{A}_{R}\left(o_{j}\right)$ the set of attributes that reject $o_{j}$, and $\mathcal{A}_{N}\left(o_{j}\right)$ attributes that

\footnotetext{
${ }^{1}$ In the case where alternatives are characterized by heteregeneous attributes, this set will depend on alternative.
} 
are neutral with regards to $o_{j}$; supporting, rejecting and neutral notions define equivalence relations over the attributes set given an objective. The basis of this approach has been laid in Tchangani (2009) with "positive" and "negative" attributes notions and in Tchangani and Pérès (2010) where authors suggest to elicit and assess attributes in a decision analysis by partitioning them into benefit (B): certain attributes that support decision objective; opportunity $(\mathrm{O})$ : uncertain attributes that support decision objective; cost $(\mathrm{C})$ : certain attributes that reject decision objective; and risk $(\mathrm{R})$ : uncertain attributes that reject decision objective; leading to a framework known as BOCR analysis. The next step towards the establishment of an evaluation model is to assess the strength of each defined relationship; this process is carried up in the next subsection using mainly analytic hierarchy process (AHP).

\subsection{Bipolar Relationships Strength Assessment Using AHP}

The basic AHP (Saaty, 1980), decomposes a decision problem in different elements grouped in clusters that it arranges in a linear hierarchy form where the top element of the hierarchy is the overall goal of the decision problem. The hierarchy goes from the general to more particular until a level of operational criteria against which the decision alternatives can be evaluated is reached. An hierarchy corresponding to our previously defined decision problem may look like that of the following Fig. 2 where $\omega^{o}$ is a $m$ dimension column vector with each entry $\omega^{o}\left(o_{j}\right)$ representing the relative importance of the corresponding objective $o_{j}$ with regard to the overall decision goal.

The vector $\omega^{o}$ can be obtained using the AHP procedure by answering questions of the form "how important is objective $o_{k}$ compared to the objective $o_{l}$ with regard to the overall decision goal ?" using the scale given by the weights of Table 1 (Saaty, 1980) to obtain a $m \times m$ matrix $\Omega^{o}$ where $\Omega^{o}(j, l)$ is the relative importance of objective $o_{j}$ compared to the objective $o_{l}$ with regard to the overall decision goal. Though, the pair-wise

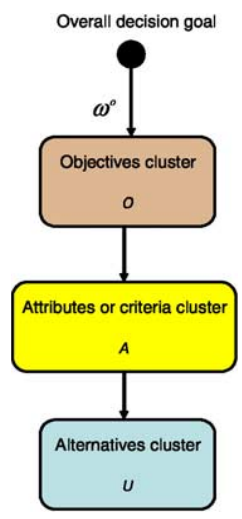

Fig. 2. An AHP model of considered decision making problem. 
Table 1

Classical AHP pair-wise comparison weights

\begin{tabular}{ll}
\hline Verbal scale & Numerical values \\
\hline Equally important & 1 \\
Moderately more important & 3 \\
Strongly more important & 5 \\
Very strongly more important & 7 \\
Extremely more important & 9 \\
Intermediate scales (compromise) & $2,4,6,8$ \\
\hline
\end{tabular}

comparison matrix $\Omega^{\circ}$ can be constructed arbitrarily and the consistency ${ }^{2}$ checked later for possible modifications, there is a straightforward approach that leads to a consistent matrix: one selects a pivot objective $o_{p}$ and compare other objectives to this pivot to obtain scores $\nu(j, p)$ (from Table 1) for all other objectives $j \neq p$ and then construct the matrix $\Omega^{\circ}$ as shown by equation (5)

$$
\begin{aligned}
& \Omega^{o}(j, p)=\nu(j, p), \quad \Omega^{o}(p, j)=\frac{1}{\nu(j, p)} \\
& \Omega^{o}(j, l)=\Omega^{o}(j, p) \Omega^{o}(p, l)=\frac{\nu(j, p)}{\nu(l, p)}
\end{aligned}
$$

where $\Omega^{o}(j, l)$ is the entry of the $j$ th raw and $l$ th column of matrix $\Omega^{o}$; and finally compute vector $\omega^{o}$ as given by equation (6)

$$
\omega^{o}\left(o_{j}\right)=\frac{1}{m} \sum_{l=1}^{m}\left(\frac{\Omega^{o}(j, l)}{\sum_{k=1}^{m}\left\{\Omega^{o}(k, l)\right\}}\right) .
$$

As stated previously, given an objective $o_{j}$, supporting/rejecting relationships will partition the set of attributes into $\mathcal{A}_{S}\left(o_{j}\right)$, the set of attributes that support objective $o_{j}$ and $\mathcal{A}_{R}\left(o_{j}\right)$ the set of attributes that reject that objective respectively, so to obtain the hierarchy of Fig. 3. Parameters shown on this Fig. 3 have the following significance: $W_{S}^{o_{j}}$ (respectively $W_{R}^{o_{j}}$ ) represents a $n \times\left|\mathcal{A}_{S}\left(o_{j}\right)\right|^{3}$ (respectively a $n \times\left|\mathcal{A}_{R}\left(o_{j}\right)\right|$ ) matrix which entry $W_{S}^{o_{j}}\left(u_{i}, a_{k}\right)$ for $a_{k} \in \mathcal{A}_{S}\left(o_{j}\right)$ (respectively $W_{R}^{o_{j}}\left(u_{i}, a_{k}\right)$ for $\left.a_{k} \in \mathcal{A}_{R}\left(o_{j}\right)\right)$ represent the evaluation of alternative $u_{i}$ over the supporting (respectively rejecting) attribute $a_{k}$ with regard to objective $o_{j}$; the entries of $\left|\mathcal{A}_{S}\left(o_{j}\right)\right|$ (respectively $\left.\left|\mathcal{A}_{R}\left(o_{j}\right)\right|\right)$ column vector $\omega_{S}^{o_{j}}$ (respectively $\omega_{R}^{o_{j}}$ ) represent the relative importance of the corresponding attributes with regard to the objective $o_{j}$ in their category.

Weighting vectors $\omega_{S}^{o_{j}}$ and $\omega_{R}^{o_{j}}$ can be determined similar to that of vector $\omega^{o}$ by comparing relative importance of corresponding attributes with regard to the objective $o_{j}$.

\footnotetext{
${ }^{2}$ A pairwise comaprison matrix $M$ is said to be consistent if it verifies $M(j, j)=1, M(j, l)=\frac{1}{M(l, j)}$ and $M(j, l)=M(j, k) M(k, l)$.

${ }^{3}$ Given a finite discret set $\mathcal{A},|\mathcal{A}|$ is its cardinality (the number of elements belonging to it).
} 


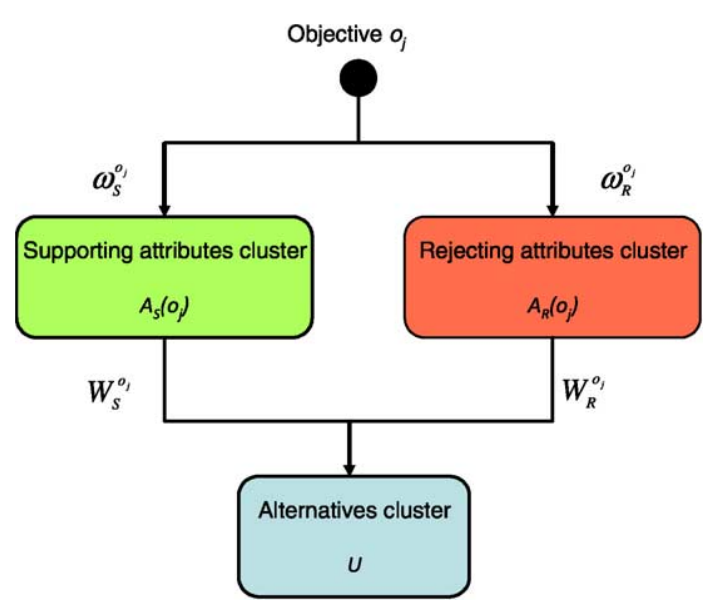

Fig. 3. Bipolar hierarchy of attributes with regard to objective $o_{j}$.

For matrices $W_{S}^{o_{j}}$ and $W_{R}^{o_{j}}$ there is two possibilities: given an attribute $a_{k}$, if alternatives are numerically evaluated over this attribute with $a_{k}\left(u_{i}\right)$ the performance of alternative $u_{i}$ with regard to $a_{k}$ then the pair-wise comparison matrix $\Omega_{\times}^{o_{j}}$ where $\times$ stands for $S$ or $R$ is obtained by equation

$$
\Omega_{\times}^{a_{k}}\left(u_{i}, u_{j}\right)=\frac{a_{k}\left(u_{i}\right)}{a_{k}\left(u_{j}\right)} ;
$$

otherwise this matrix is obtained using a AHP procedure as previously stated by answering a question of the form "how well does perform alternative $u_{i}$ compared to alternative $u_{j}$ with regard to attribute $a_{k}$ ?" and finally the entry $W_{\times}^{o_{j}}\left(u_{i}, a_{k}\right)$ is obtained by equation

$$
W_{\times}^{o_{j}}\left(u_{i}, a_{k}\right)=\frac{1}{n} \sum_{j}\left(\frac{\Omega_{\times}^{a_{k}}\left(u_{i}, u_{j}\right)}{\sum_{k} \Omega_{\times}^{a_{k}}\left(u_{k}, u_{j}\right)}\right) .
$$

A more complete model can be derived by using analytic hierarchy process (ANP) to cope with possible reflexivity relationships that may exist between elements within a same cluster (Saaty, 2005); this approach has been considered in Tchangani (2006) in the framework of satisficing game theory to establish a new multi-attributes decision approach.

In the next section, the final procedure of evaluation and recommendation will be considered.

\section{Evaluation and Recommendation Procedures}

Bipolar nature of attributes with regard to objectives suggest an evaluation model towards two direction: the achievement of objectives and forces competing this achievement. Evaluation process that consists in confronting positive and negative aspects of 
alternative is common in human decision making activities in almost all socioeconomic domains; the formalization of such practices is therefore necessary. An interesting framework for this formalization is the satisficing game theory; so this section begins by recalling basics of this theory that are relevant to the purpose of this paper and then used them to establish the ultimate evaluation and recommendation procedures of the considered decision problem.

\subsection{Satisficing Game Theory}

The main philosophy of satisficing game theory relies on the fact that, most of the time humans content themselves with alternatives that are just "good enough" because their cognitive capacities are limited and information in their possession is almost always imperfect; this is the fundamental idea behind the theory of bounded rationality that has its roots in the work by Simon (1997); the concept of being good enough allows a certain flexibility because one can always adjust its aspiration level. This concept is suitable for the approach considered in this paper as being good enough for an alternative can simply signify that the supporting contribution exceeds the rejecting one in some sense. This way of evaluation falls into the framework of praxeology or the study of theory of practical activity (the science of efficient action). For a universe $\mathcal{U}$ of alternatives, one will define for each alternative $u \in \mathcal{U}$, a selectability function or measure $\mu_{S}(u)$ and a rejectability function or measure $\mu_{R}(u)$ to measure the degree to which $u$ works towards success in achieving the decision maker's goal and costs associated with this alternative respectively. This pair of measures called satisfiability functions are mass functions (they have the mathematical structure of probabilities; Stirling, 2003): they are non negative and sum to one over $\mathcal{U}$. The following definition then gives the set of alternatives arguable to be "good enough" because for these options, the "benefit" expressed by the function $\mu_{S}$ exceeds the cost expressed by the function $\mu_{R}$ with regard to an index of caution $q$.

DEFINITION 4. The satisficing set $\Sigma_{q} \subseteq \mathcal{U}$ is the set of alternatives defined by the following equation

$$
\Sigma_{q}=\left\{u \in \mathcal{U}: \mu_{S}(u) \geqslant q \mu_{R}(u)\right\} .
$$

The caution index $q$ can be used to adjust the aspiration level: increase $q$ if too many alternatives are declared satisficing or on the contrary decrease $q$ if $\Sigma_{q}$ is empty for instance.

But for a satisficing alternative $u$ there can exist other satisficing alternatives that are better (having more selectability and at most the same rejectability or having less rejectability and at least the same selectability) than $u$; it is obvious that in this case any rational decision maker will prefer the later alternatives. So the interesting set is that containing satisficing alternatives for which there are no better alternatives: this is the satisficing equilibrium set $\mathcal{E}_{q}^{S}$. To define this set, let us define first, for any alternative $u \in \mathcal{U}$, the set $\mathcal{D}(u)$ of alternatives that are strictly better than $u ; \mathcal{D}(u)$ is given by 
equation (10)

$$
\mathcal{D}(u)=\mathcal{D}_{S}(u) \cup \mathcal{D}_{R}(u),
$$

where $\mathcal{D}_{S}(u)$ and $\mathcal{D}_{R}(u)$ are defined by equations

$$
\begin{aligned}
& \mathcal{D}_{S}(u)=\left\{v \in \mathcal{U}: \mu_{R}(v)<\mu_{R}(u) \& \mu_{S}(v) \geqslant \mu_{S}(u)\right\}, \\
& \mathcal{D}_{R}(u)=\left\{v \in \mathcal{U}: \mu_{R}(v) \leqslant \mu_{R}(u) \& \mu_{S}(v)>\mu_{S}(u)\right\} .
\end{aligned}
$$

The equilibrium set $\mathcal{E}$ (alternatives for which there are no strictly better alternatives), which can not be empty by definition, is defined by equation (13)

$$
\mathcal{E}=\{u \in \mathcal{U}: \mathcal{D}(u)=\varnothing\}
$$

and the satisficing equilibrium set, $\mathcal{E}_{q}^{S}$ is given by equation (14)

$$
\mathcal{E}_{q}^{S}=\mathcal{E} \cap \Sigma_{q}
$$

Notice that $\mathcal{E}_{q}^{S}$ constitutes a Pareto-equilibria set so that there is incomparability between a pair of alternatives in this set, so that a trade-off process is necessary for final choice purpose for instance.

Defining a decision analysis problem as a satisficing game return to finding a way to derive satisfiability measures; the following paragraph presents how to compute these measures for decision problem considered in this paper.

\subsection{Satisfiability Functions of the Considered Decision Problem}

The stepping stones of a satisficing game are satisfiability measures or functions. Using materials obtained in modelling and assessment section, satisfiability measures can be derived straightforwardly as given by the following definition.

DEFINITION 5. The satisfiability functions $\mu_{S}$ and $\mu_{R}$ are defined by equations (15)(16)

$$
\begin{aligned}
& \mu_{S}\left(u_{i}\right)=\sum_{o_{j} \in \mathcal{O}}\left\{\omega^{o}\left(o_{j}\right)\left\{\sum_{a_{k} \in \mathcal{A}_{S}\left(o_{j}\right)}\left\{\omega_{S}^{o_{j}}\left(a_{k}\right) W_{S}^{o_{j}}\left(u_{i}, a_{k}\right)\right\}\right\},\right. \\
& \mu_{R}\left(u_{i}\right)=\sum_{o_{j} \in \mathcal{O}}\left\{\omega^{o}\left(o_{j}\right)\left\{\sum_{a_{k} \in \mathcal{A}_{R}\left(o_{j}\right)}\left\{\omega_{R}^{o_{j}}\left(a_{k}\right) W_{R}^{o_{j}}\left(u_{i}, a_{k}\right)\right\}\right\}\right\} .
\end{aligned}
$$

It is obvious that $\mu_{S}$ and $\mu_{R}$ fulfill the requirements of satisfiability measures. Based on these measures, one will obtain the satisficing equilibria set $\mathcal{E}_{q}^{S}$ from which a final alternative can be selected in the case of choosing process; the following paragraph considers some possible recommendation procedures. Of course, one can imagine other possibilities. 


\subsection{Recommendation Procedures}

Choosing and ranking are relative evaluation operations (Bouyssou et al., 2000) over the alternatives set $\mathcal{U}$; based on the previously derived materials, an obvious value function $\pi(u), \forall u \in \mathcal{U}$ can be defined as a function of the satisfiability measures $\mu_{S}(u)$ and $\mu_{R}(u)$, that is

$$
\pi(u)=\pi\left(\mu_{S}(u), \mu_{R}(u)\right)
$$

which can take particular form depending on the decision goal. Here is some of these possible forms

$$
\pi(u)=\mu_{S}(u)-q \mu_{R}(u)
$$

that gives the priority to alternatives with large difference between the selectability measure and the rejectability measure given the index of caution $q$, or

$$
\pi(u)=\frac{\mu_{S}(u)}{\mu_{R}(u)}
$$

that considers alternatives with the largest index of caution, or

$$
\pi(u)=\mu_{S}(u)\left(\operatorname{respect} . \pi(u)=\frac{1}{\mu_{R}(u)}\right),
$$

that gives priority to alternatives with the largest selectability (respect. lowest rejectability); this later case is suitable when one of the measure is uniformly distributed over alternatives. This value function can then be used to select the ultimate alternative $u^{*}$ as shown by equation (21)

$$
u^{*}=\arg \max _{v \in \mathcal{E}_{q}^{S}} \pi(v)
$$

or to rank alternatives using the relation given by equation

$$
u \succeq v \Longleftrightarrow \pi(u) \geqslant \pi(v)
$$

Sorting is an absolute operation (Bouyssou et al., 2000) that requires defining norms and categories; different norms can be derived by using the value function $\pi(u)$. For instance, in the case $\pi(u)=\mu_{S}(u)-q \mu_{R}(u)$, two natural partitions of $\mathcal{U}$ are given by equation (23)

$$
\mathcal{C}_{1}=\Sigma_{q}=\{u \in \mathcal{U}: \pi(u) \geqslant 0\} \quad \text { and } \quad \mathcal{C}_{2}=\mathcal{U}-\mathcal{C}_{1}
$$

Besides this possibility of sorting, the satisficing game approach leads to a natural categorization of the alternatives set $\mathcal{U}$ into four subsets, namely $\mathcal{E}_{q}^{S}, \mathcal{E}-\mathcal{E}_{q}^{S}, \Sigma_{q}-\mathcal{E}_{q}^{S}$, and 
$\mathcal{U}-\Sigma_{q} \cup \mathcal{E}$. In terms of preference the subset $\mathcal{E}_{q}^{S}$ is obviously preferred to the rest: it contains alternatives arguable to be "best good enough" (their selectability exceeds their rejectability and there are no alternatives that are better than them) and the set $\mathcal{U}-\Sigma_{q} \cup \mathcal{E}$ contains completely inefficient alternatives (they are not satisficing alternatives nor equilibrium); there is no obvious conclusion for the subsets $\mathcal{E}-\mathcal{E}_{q}^{S}$ and $\Sigma_{q}-\mathcal{E}_{q}^{S}$ and a sensitivity analysis can be done for these alternatives, see for instance Tchangani (2009).

To show the applicability of the approach established so fare step by step, we consider a decision problem in manufacturing domain; the purpose here is to choose or justify the best practice in terms of manufacturing management model (technology oriented model, management oriented model or traditional model).

\section{Example of Application}

\subsection{Description}

The materials of this application are extracted from Gurumurthy and Kodali (2007) and Gurumurthy and Kodali (2008) and adapted to the approach established in this paper. In Gurumurthy and Kodali (2007) and Gurumurthy and Kodali (2008), a performance value analysis approach is used to justify the adoption of a management oriented manufacturing approach in terms of lean manufacturing system (LMS) in comparison to a technology oriented manufacturing approach such as computer integrated manufacturing system (CIMS) and a traditional manufacturing system (TMS) using some indicators such as productivity, competitiveness, flexibility, innovation, etc. which are evaluated through a certain number of attributes obtained through interviews of managers. The result was that using these indicators and performances of attributes for each of these three manufacturing systems, LMS outranks CIMS that in return outranks TMS. To conform to the framework established in this paper we re-organize the materials from Gurumurthy and Kodali (2007) and Gurumurthy and Kodali (2008) as given in the following paragraphs.

\subsubsection{Objectives}

We have identified five objectives that correspond to main indicators considered in Gurumurthy and Kodali (2007) and Gurumurthy and Kodali (2008); they are:

- $o_{1}$ - productivity objective,

- $\mathrm{O}_{2}$ - social objective,

- $o_{3}$ - competitiveness objective,

- $o_{4}$ - flexibility objective,

- $o_{5}$ - innovation objective.

\subsubsection{Alternatives}

There are obviously 3 alternatives as stated previously defined as:

- $u_{1}$ - traditional manufacturing system (TMS);

- $u_{2}$ - technology oriented system in terms of computers integrated manufacturing system (CIMS);

- $u_{3}$ - management oriented system in terms of lean manufacturing system (LMS). 


\subsubsection{Attributes}

Different attributes used in Gurumurthy and Kodali (2007) and Gurumurthy and Kodali (2008) for each objective are reorganized in terms of supporting and rejecting and their performance matrices as well as normalized matrices $W_{\times}^{o_{j}}$ and weights $\omega_{\times}^{o_{j}}$ given below.

\subsubsection{Attributes to evaluate productivity objective}

Supporting attributes of productivity objective

- Labour productivity (LAP, in \%).

- Number of inventory or stock rotations (SRO, in Nos.).

- Production capacity (PRC, in number of units per year).

- Overall Equipment Efficiency (OEE, in \%)).

- Equipment utilization (EQU, in \%).

- Overall productivity (OPR).

- Labour utilization (LAU, in \%).

- Utilization of capacity (UTC, in \%).

- Production rate (PRR).

- Production volume (PRV).

- Material productivity (MAP, in \%).

- Machine productivity (MCP, in \%).

- Value added time (VAT, in hours).

- Average operation time per week (AVT, in days).

- Reliability of machines (REL, in \%).

Performance matrix for supporting attributes of productivity objective (Table 2)

Rejecting attributes of productivity objective

- Manufacturing cycle time (MCT, in hours).

- Total floor space (TFS, in $\mathrm{m}^{2}$ ).

- Number of stages in the overall material flow (RNS, in Nos.).

- Number of bottleneck stages (NOB, in Nos.).

- Maintenance time (RMT, in hours per week).

- Non value added time (NVA, in days).

- Percentage of unscheduled downtime or equipment breakdown time (USD, in \%).

- Takt time (TAK, in hours).

Performance matrix for rejecting attributes of productivity objective (Table 3)

4.1.3.2. Attributes to evaluate social objective

\section{Supporting attributes of social objective}

- Number of awards and rewards provided for workers (REC, in Nos.).

- Percentage of inspection carried out by autonomous defect control (ICA, in \%).

- Number of teams (TEA, in Nos.).

- Percentage of employees working in team (EWT, in \%).

- Reduction in number of workers (RNW). 
Table 2

Supporting attributes of productivity objective

\begin{tabular}{|c|c|c|c|c|}
\hline Attributes & TMS & CIMS & LMS & $\begin{array}{l}\text { Attributes } \\
\text { weights }\end{array}$ \\
\hline LAP & 78 & 90 & 85 & 1 \\
\hline SRO & 6 & 10 & 12 & 1 \\
\hline PRC & 10,000 & 14,000 & 11,000 & 1 \\
\hline OEE & 42 & 65 & 75 & 1 \\
\hline EQU & 73 & 80 & 85 & 1 \\
\hline OPR & Low & Medium & High & 1 \\
\hline LAU & 86 & 80 & 90 & 1 \\
\hline UTC & 83 & 85 & 80 & 1 \\
\hline PRR & Low & High & Medium & 1 \\
\hline PRV & Low & High & Medium & 1 \\
\hline MAP & 82 & 85 & 90 & 1 \\
\hline MCP & 78 & 85 & 90 & 1 \\
\hline VAT & 4.5 & 6 & 6.5 & 1 \\
\hline AVT & 4.1 & 5 & 5.51 & 1 \\
\hline \multirow[t]{2}{*}{ REL } & 74 & 85 & 80 & 1 \\
\hline & $W_{S}^{o_{1}}$ & & & $\omega_{S}^{o_{1}}$ \\
\hline LAP & 0.3083 & 0.3557 & 0.3360 & 0.0667 \\
\hline SRO & 0.2143 & 0.3571 & 0.4286 & 0.0667 \\
\hline PRC & 0.2857 & 0.4000 & 0.3143 & 0.0667 \\
\hline OEE & 0.2308 & 0.3571 & 0.4121 & 0.0667 \\
\hline EQU & 0.3067 & 0.3361 & 0.3571 & 0.0667 \\
\hline OPR & 0.0667 & 0.3333 & 0.6000 & 0.0667 \\
\hline LAU & 0.3359 & 0.3125 & 0.3516 & 0.0667 \\
\hline UTC & 0.3347 & 0.3427 & 0.3226 & 0.0667 \\
\hline PRR & 0.0667 & 0.6000 & 0.3333 & 0.0667 \\
\hline PRV & 0.0667 & 0.6000 & 0.3333 & 0.0667 \\
\hline MAP & 0.3191 & 0.3307 & 0.3502 & 0.0667 \\
\hline MCP & 0.3083 & 0.3360 & 0.3557 & 0.0667 \\
\hline VAT & 0.2647 & 0.3529 & 0.3824 & 0.0667 \\
\hline AVT & 0.2808 & 0.3425 & 0.3767 & 0.0667 \\
\hline REL & 0.3096 & 0.3556 & 0.3347 & 0.0667 \\
\hline
\end{tabular}

- Amount of training (TRH, in number of days/year).

- Use of visual management or aids (VMA).

- Level of housekeeping (HOK).

- Condition of work environment (WOE).

- Worker morale and satisfaction (WMS).

- Communication between employees and management (COM).

- Percentage of people involving in stopping the line due to problems (PSL, in \%). 
Table 3

Rejecting attributes of productivity objective

\begin{tabular}{lllll}
\hline Attributes & TMS & CIMS & LMS & $\begin{array}{l}\text { Attributes } \\
\text { weights }\end{array}$ \\
\hline MCT & 0.6 & 0.35 & 0.4 & 1 \\
TFS & 1200 & 1000 & 950 & 1 \\
RNS & 14 & 12 & 11 & 1 \\
NOB & 4 & 2 & 2 & 1 \\
RMT & 26 & 28 & 20 & 1 \\
NVA & 3 & 2 & 1 & 1 \\
USD & 33 & 25 & 20 & 1 \\
TAK & 0.5 & 0.35 & 0.3 & 1 \\
NVA & 3 & 2 & 1 & 1 \\
USD & 33 & 25 & 20 & 1 \\
TAK & 0.5 & 0.35 & 0.3 & 1 \\
\hline & $W_{R}^{O_{1}}$ & & & $\omega_{R}^{o_{1}}$ \\
\hline MCT & 0.4444 & 0.2593 & 0.2963 & 0.1250 \\
TFS & 0.3810 & 0.3175 & 0.3016 & 0.1250 \\
RNS & 0.3784 & 0.3243 & 0.2973 & 0.1250 \\
NOB & 0.5000 & 0.2500 & 0.2500 & 0.1250 \\
RMT & 0.3514 & 0.3784 & 0.2703 & 0.1250 \\
NVA & 0.5000 & 0.3333 & 0.1667 & 0.1250 \\
USD & 0.4231 & 0.3205 & 0.2564 & 0.1250 \\
TAK & 0.4348 & 0.3043 & 0.2609 & 0.1250 \\
\hline & & & &
\end{tabular}

Performance matrix for supporting attributes of social objective (Table 4)

Rejecting attributes of social objective

- Direct labour (DIL, in Nos.).

- Indirect labour (IDL, in Nos.).

- Number of workers/employees (NOW, in Nos.).

- Employee turnover rate (ETR).

- Number of shifts or working hours (RWH, in Nos.).

- Hierarchy in the organization structure (HIE, in Nos.).

- Absenteeism rate (ABM).

- Number of accidents (NOA, in Nos.).

- Overtime per week (OVE, in days).

Performance matrix for rejecting attributes of social objective (Table 5)

4.1.3.3. Attributes to evaluate competitiveness objective

Supporting attributes of competitiveness objective

- Gross annual profit (GRP, in lakhs of Rs.).

- Total sales (TOS, in lakhs of Rs.). 
Table 4

Supporting attributes of social objective

\begin{tabular}{|c|c|c|c|c|}
\hline Attributes & TMS & CIMS & LMS & $\begin{array}{l}\text { Attributes } \\
\text { weights }\end{array}$ \\
\hline REC & 6 & 8 & 12 & 7 \\
\hline ICA & 24 & 90 & 95 & 7 \\
\hline TEA & 4 & 6 & 9 & 7 \\
\hline EWT & 20 & 50 & 70 & 6 \\
\hline RNW & Low & High & Medium & 7 \\
\hline TRH & 14 & 24 & 30 & 7 \\
\hline VMA & Low & Medium & High & 7 \\
\hline $\mathrm{HOK}$ & Low & Medium & High & 7 \\
\hline WOE & Poor & Fair & Good & 6 \\
\hline WMS & Low & Medium & High & 7 \\
\hline $\mathrm{COM}$ & Low & Medium & High & 7 \\
\hline \multirow[t]{2}{*}{ PSL } & 12 & 15 & 25 & 7 \\
\hline & $W_{S}^{o_{2}}$ & & & $\omega_{S}^{o_{2}}$ \\
\hline REC & 0.2308 & 0.3077 & 0.4615 & 0.0854 \\
\hline ICA & 0.1148 & 0.4306 & 0.4545 & 0.0854 \\
\hline TEA & 0.2105 & 0.3158 & 0.4737 & 0.0854 \\
\hline EWT & 0.1429 & 0.3571 & 0.5000 & 0.0732 \\
\hline RNW & 0.0667 & 0.6000 & 0.3333 & 0.0854 \\
\hline TRH & 0.2059 & 0.3529 & 0.4412 & 0.0854 \\
\hline VMA & 0.0667 & 0.3333 & 0.6000 & 0.0854 \\
\hline $\mathrm{HOK}$ & 0.0667 & 0.3333 & 0.6000 & 0.0854 \\
\hline WOE & 0.0667 & 0.3333 & 0.6000 & 0.0732 \\
\hline WMS & 0.0667 & 0.3333 & 0.6000 & 0.0854 \\
\hline $\mathrm{COM}$ & 0.0667 & 0.3333 & 0.6000 & 0.0854 \\
\hline PSL & 0.2308 & 0.2885 & 0.4808 & 0.0854 \\
\hline
\end{tabular}

- Revenue (REV, in lakhs of Rs.).

- Customer good will (CGW).

- Market share (MAS, in \%).

- Brand image (BRI).

- Dividends paid to shareholders (DTS, in \%).

- Return on assets (ROA).

- Customer satisfaction (CUS).

- Time-based competitiveness (TBC).

Performance matrix for supporting attributes of competitiveness objective (Table 6)

Rejecting attributes of competitiveness objective

- Loss of customers (LOC).

- Price of the product (PRI, in lakhs of Rs.).

- Lost sales (LOS). 
Table 5

Rejecting attributes of social objective

\begin{tabular}{lllll}
\hline Attributes & TMS & CIMS & LMS & $\begin{array}{l}\text { Attributes } \\
\text { weights }\end{array}$ \\
\hline DIL & 42 & 35 & 35 & 8 \\
IDL & 38 & 30 & 35 & 8 \\
NOW & 80 & 75 & 70 & 8 \\
ETR & High & Medium & Low & 6 \\
RWH & 3 & 2 & 2 & 6 \\
HIE & 6 & 5 & 4 & 5 \\
ABM & High & Medium & Low & 6 \\
NOA & High & Low & Low & 6 \\
OVE & 2 & 1 & 0.5 & 7 \\
\hline & $W_{R}^{o_{2}}$ & & & $\omega_{R}^{o_{2}}$ \\
\hline DIL & 0.3750 & 0.3125 & 0.3125 & 0.1333 \\
IDL & 0.3689 & 0.2913 & 0.3398 & 0.1333 \\
NOW & 0.3556 & 0.3333 & 0.3111 & 0.1333 \\
ETR & 0.6000 & 0.3333 & 0.0667 & 0.1000 \\
RWH & 0.4286 & 0.2857 & 0.2857 & 0.1000 \\
HIE & 0.4000 & 0.3333 & 0.2667 & 0.0833 \\
ABM & 0.6000 & 0.3333 & 0.0667 & 0.1000 \\
NOA & 0.8182 & 0.0909 & 0.0909 & 0.1000 \\
OVE & 0.5714 & 0.2857 & 0.1429 & 0.1167 \\
\hline & & & &
\end{tabular}

Performance matrix for rejecting attributes of competitiveness objective (Table 7)

4.1.3.4. Attributes to evaluate flexibility objective

Supporting attributes of flexibility objective

- Availability of reserve capacity (ARC).

- Percentage of flexible employees cross trained to perform three or more jobs (FEM, in $\%$ ).

- Percentage of production equipment that is computer integrated or automated (AUT, in \%).

- Overall flexibility (OFX).

- Number of mixed models in a line (NMM, in Nos.).

- Frequency of die changes (FDC).

Performance matrix for supporting attributes of flexibility objective (Table 8)

Rejecting attributes of flexibility objective

- Work in process inventory (WIP, in days).

- Setup time (SET, in hours). 
Table 6

Supporting attributes of competitiveness objective

\begin{tabular}{|c|c|c|c|c|}
\hline Attributes & TMS & CIMS & LMS & $\begin{array}{l}\text { Attributes } \\
\text { weights }\end{array}$ \\
\hline GRP & 240 & 300 & 305 & 10 \\
\hline TOS & 550 & 650 & 675 & 9 \\
\hline REV & 600 & 675 & 700 & 9 \\
\hline CGW & Low & Medium & High & 7 \\
\hline MAS & 22 & 25 & 28 & 8 \\
\hline BRI & Medium & High & High & 8 \\
\hline DTS & 8 & 10 & 11 & 7 \\
\hline ROA & Low & Medium & High & 6 \\
\hline CUS & Low & Medium & High & 8 \\
\hline \multirow[t]{2}{*}{ TBC } & Low & High & High & 7 \\
\hline & $W_{S}^{o_{3}}$ & & & $\omega_{S}^{o_{3}}$ \\
\hline GRP & 0.2840 & 0.3550 & 0.3609 & 0.1266 \\
\hline TOS & 0.2933 & 0.3467 & 0.3600 & 0.1139 \\
\hline REV & 0.3038 & 0.3418 & 0.3544 & 0.1139 \\
\hline CGW & 0.0667 & 0.3333 & 0.6000 & 0.0886 \\
\hline MAS & 0.2933 & 0.3333 & 0.3733 & 0.1013 \\
\hline BRI & 0.2174 & 0.3913 & 0.3913 & 0.1013 \\
\hline DTS & 0.2759 & 0.3448 & 0.3793 & 0.0886 \\
\hline ROA & 0.0667 & 0.3333 & 0.6000 & 0.0759 \\
\hline CUS & 0.0667 & 0.3333 & 0.6000 & 0.1013 \\
\hline $\mathrm{TBC}$ & 0.0526 & 0.4737 & 0.4737 & 0.0886 \\
\hline
\end{tabular}

Table 7

Rejecting attributes of competitiveness objective

\begin{tabular}{lllll}
\hline Attributes & TMS & CIMS & LMS & $\begin{array}{l}\text { Attributes } \\
\text { weights }\end{array}$ \\
\hline LOC & Low & Medium & High & 6 \\
PRI & 0.6 & 0.35 & 0.3 & 8 \\
LOS & High & Medium & Low & 7 \\
\hline & $W_{R}^{o_{3}}$ & & & $\omega_{R}^{o_{3}}$ \\
\hline LOC & 0.0667 & 0.3333 & 0.6000 & 0.2857 \\
PRI & 0.4800 & 0.2800 & 0.2400 & 0.3810 \\
LOS & 0.0667 & 0.3333 & 0.6000 & 0.3333
\end{tabular}


Table 8

Supporting attributes of flexibility objective

\begin{tabular}{lllll}
\hline Attributes & TMS & CIMS & LMS & $\begin{array}{l}\text { Attributes } \\
\text { weights }\end{array}$ \\
\hline ARC & Low & Medium & High & 7 \\
FEM & 18 & 25 & 30 & 8 \\
AUT & 10 & 60 & 20 & 8 \\
OFX & Low & Medium & High & 6 \\
NMM & 1 & 5 & 5 & 7 \\
FDC & Low & Medium & High & 7 \\
\hline & $W_{S}^{o} 4$ & & & $\omega_{S}^{o 4}$ \\
\hline ARC & 0.0667 & 0.3333 & 0.6000 & 0.1628 \\
FEM & 0.2466 & 0.3425 & 0.4110 & 0.1860 \\
AUT & 0.1111 & 0.6667 & 0.2222 & 0.1860 \\
OFX & 0.0667 & 0.3333 & 0.6000 & 0.1395 \\
NMM & 0.0909 & 0.4545 & 0.4545 & 0.1628 \\
FDC & 0.0667 & 0.3333 & 0.6000 & 0.1628 \\
\hline
\end{tabular}

- Finished goods inventory (FGI, in days).

- Batch size (BAS).

- Length of product runs (LPR).

- Raw material inventory (RMI, in days).

Performance matrix for rejecting attributes of flexibility objective (Table 9)

4.1.3.5. Attributes to evaluate innovation objective

Supporting attributes of innovation objective

- Number of suggestions per employee per year (SUG, in Nos.).

- Percentage of parts co-designed with suppliers (PCS, in \%).

- Number of new products introduced (NNP, in Nos.).

- R\&D Expenditure as a percentage of turnover (RDE, in \%).

- Percentage of common or standardized parts (COP, in \%).

Performance matrix for supporting attributes of innovation objective (Table 10)

Rejecting attributes of innovation objective

- Time to market for new products (TTM, in years).

- Time spent on engineering changes (TEC, in days).

- Total parts in Bill of Materials (NOP).

Performance matrix for rejecting attributes of innovation objective (Table 11) 
Table 9

Rejecting attributes of flexibility objective

\begin{tabular}{lllll}
\hline Attributes & TMS & CIMS & LMS & $\begin{array}{l}\text { Attributes } \\
\text { weights }\end{array}$ \\
\hline WIP & 20 & 14 & 10 & 9 \\
SET & 8 & 6.5 & 5 & 10 \\
FGI & 12 & 9 & 7 & 9 \\
BAS & High & Medium & Low & 8 \\
LPR & High & Medium & Low & 7 \\
RMI & 15 & 8 & 6 & 9 \\
\hline & $W_{R}^{o 4}$ & & & $\omega_{R}^{o_{4}}$ \\
\hline WIP & 0.4545 & 0.3182 & 0.2273 & 0.1731 \\
SET & 0.4103 & 0.3333 & 0.2564 & 0.1923 \\
FGI & 0.4286 & 0.3214 & 0.2500 & 0.1731 \\
BAS & 0.6000 & 0.3333 & 0.0667 & 0.1538 \\
LPR & 0.6000 & 0.3333 & 0.0667 & 0.1346 \\
RMI & 0.5172 & 0.2759 & 0.2069 & 0.1731 \\
\hline
\end{tabular}

Table 10

Supporting attributes of innovation objective

\begin{tabular}{lllll}
\hline Attributes & TMS & CIMS & LMS & $\begin{array}{l}\text { Attributes } \\
\text { weights }\end{array}$ \\
\hline SUG & 20 & 35 & 55 & 8 \\
PCS & 7 & 14 & 20 & 7 \\
NNP & 3 & 4 & 5 & 8 \\
RDE & 13 & 20 & 22 & 8 \\
COP & 8 & 14 & 16 & 7 \\
\hline & $W_{S}^{o_{5}}$ & & & $\omega_{S}^{o_{5}}$ \\
\hline SUG & 0.1818 & 0.3182 & 0.5000 & 0.2105 \\
PCS & 0.1707 & 0.3415 & 0.4878 & 0.1842 \\
NNP & 0.2500 & 0.3333 & 0.4167 & 0.2105 \\
RDE & 0.2364 & 0.3636 & 0.4000 & 0.2105 \\
COP & 0.2105 & 0.3684 & 0.4211 & 0.1842 \\
\hline
\end{tabular}

\subsection{Results}

From different performance and weights matrices, a AHP analysis through (7) and (8) for each category has been done to obtain the evaluation of each alternative with regard to attributes in terms of matrices $W_{\times}^{o_{j}}\left(u_{i}, a_{k}\right)$ and $\omega_{\times}^{o_{j}}$; to this end qualitative evaluations 
Table 11

Rejecting attributes of innovation objective

\begin{tabular}{lllll}
\hline Attributes & TMS & CIMS & LMS & $\begin{array}{l}\text { Attributes } \\
\text { weights }\end{array}$ \\
\hline TTM & 4 & 3.5 & 3 & 7 \\
TEC & 3 & 2 & 1 & 5 \\
NOP & High & Medium & Low & 6 \\
\hline & $\|_{\mathrm{c} W_{R}^{O_{5}}}$ & & & $\omega_{R}^{O_{5}}$ \\
\hline TTM & 0.3810 & 0.3333 & 0.2857 & 0.3889 \\
TEC & 0.5000 & 0.3333 & 0.1667 & 0.2778 \\
NOP & 0.6000 & 0.3333 & 0.0667 & 0.3333
\end{tabular}

Table 12

Selectability and rejectability measures for the considered application

\begin{tabular}{llll}
\hline $\begin{array}{l}\text { Satisfiability } \\
\text { measures }\end{array}$ & TMS & CIMS & LMS \\
\hline$\mu_{S}$ & 0.1802 & 0.3721 & 0.4478 \\
$\mu_{R}$ & 0.4247 & 0.3133 & 0.2620 \\
\hline
\end{tabular}

are converted to numerical evaluation using the conversion rules considered in Gurumurthy and Kodali (2007) and Gurumurthy and Kodali (2008), that is Low/Poor = 1; Medium/Fair $=5 ;$ High/Good $=9$; finally, considering all objectives to have the same importance, that is the vector $\omega^{o}$ is given by equation (24)

$$
\omega^{o}=\left[\begin{array}{lllll}
0.2 & 0.2 & 0.2 & 0.2 & 0.2
\end{array}\right]^{T}
$$

selectability measure $\mu_{S}$ and rejectability measure $\mu_{R}$ are computed by (15)-(16) and the results are given in the following Table 12 and also depicted on Fig. 4.

Showing alternatives positions in the plane $\left(\mu_{R}, \mu_{S}\right)$ as Fig. 4, may be of a great aid for analysis (mainly when there are a great number of alternatives) as this allows to visualize equilibria, satisficing, not satisficing alternatives, and for a particular alternative one can determine alternatives that may dominate it; this information can be used to guide a sensitivity analysis process for trade-off seeking for instance. One can see from Fig. 4 that alternative LMS is the unique satisficing equilibrium at the caution index $q=1$ because it dominates the two other alternatives CIMS and TMS; furthermore CIMS dominates TMS so that the ultimate dominance structure is given by equation

$$
\text { LMS } \succ \text { CIMS } \succ \text { TMS }
$$




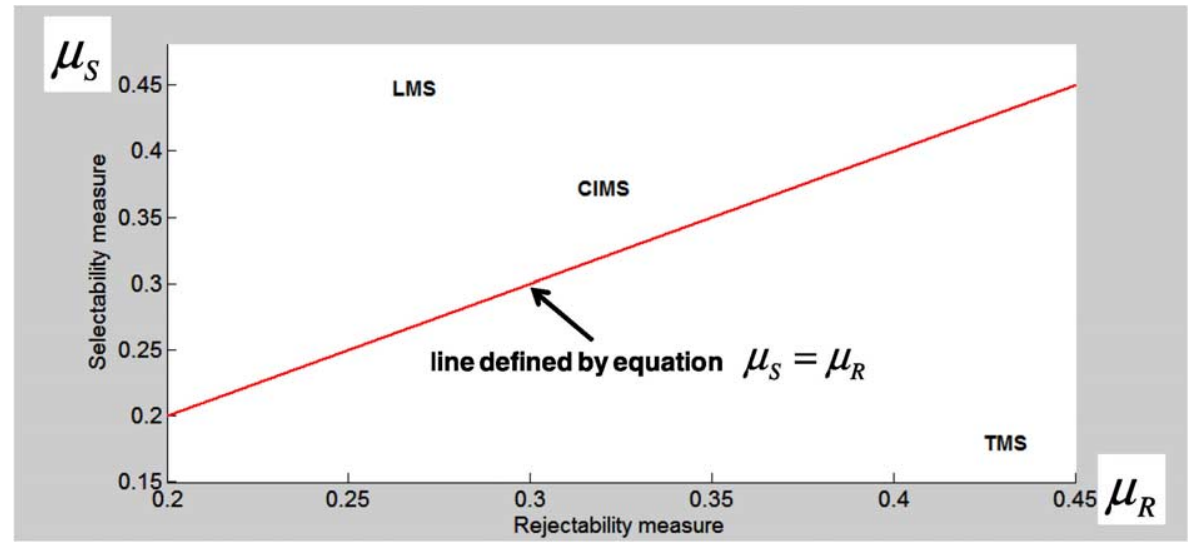

Fig. 4. Positions of alternatives in (rejectability, selectability) plane.

where " $\succ$ " stands for "is better than". Given this dominance structure there is no need to use complex recommendation procedures as that developed at Section 3.3 for final decision making.

\section{Generalizing Conclusion}

The problem of constructing an evaluation model for decision analysis where a certain number of objectives must be satisfied and where alternatives are characterized by multiple attributes or criteria is considered in this paper. The philosophy behind the established model highlights bipolarity that characterize relationships between attributes or criteria and objectives in a decision analysis problem. Indeed, given an objective, there will be attributes that work towards the achievement of this objective (referred to as supporting attributes) and attributes that work in the opposite sense (known as rejecting attributes). Given this distinction, an appropriate framework identified in the literature to formulate the evaluation model is that of satisficing game. So the established evaluation model consist in separating and aggregating separately, given an alternative, the supporting strength and the rejecting one. Supporting and rejecting relationships degrees are assessed using the well known analytic hierarchy process (AHP). By so doing, though it has not been explicitly considered in this paper, alternatives can be characterized by heterogeneous attributes making it suitable for use in many socioeconomic decision making contexts. Application of the established approach to a real world problem has shown its effectiveness.

\section{References}

Antucheviciene, J., Zakarevicius, A., Zavadskas, E.K. (2011). Measuring congruence of ranking results applying particular MCDM methods. Informatica, 22(3), 319-338. 
Basak, I.(2011). An alternate method of deriving priorities and related inferences for group decision making in analytic hierarchy process. Journal of Multi-Criteria Decision Analysis, 18(5-6), 279-287.

Bouyssou, D., Marchant, T., Perny, P.,Pirlot, M. , Tsoukiàs, A., Vincke, P. (2000). Evaluation and Decision Models: A critical Perspective. Kluwer Academic, Dordrecht.

Caciopo, J.T., Berntson, G.G. (1994). Relationship between attitudes and evaluative space: a critical review, with emphasis on the separability of positive and negative substrates. Psychological Bulletin, 115, 401-423.

Doumpos, M., Zanakis, S.H., Zopounidis, C. (2001). Multicriteria preference disaggregation for classification problems with an application to global investing risk. Decision Sciences, 32(2), 333-386.

Dubois, D., Fargier, H. (2006). Qualitative decision making with bipolar information. American Association for Artificial Intelligence (www . aaai .org).

Greco, S., Matarazzo, B., Slowinski, R. (2001). Rough sets theory for multicriteria decision analysis. European Journal of Operational Research, 129(1), 1-47.

Geldermann, J., Rentz, O. (2003). Environmental decisions and electronic democracy. Journal of Multi-Criteria Decision Analysis, 12(2-3), 77-92.

Gurumurthy, A., Kodali, R. (2007). Performance value analysis for the justification of lean manufacturing systems. In: Proceedings of the 2007 IEEE IEEM, pp. 377-381.

Gurumurthy, A., Kodali, R. (2008). A multi-criteria decision-making model for the justification of lean manufacturing systems. International Journal of Management Science and Engineering Management, 3(2), 100118.

Jacquet-Lagrèze, E., Sisko, J. (1982). Assessing a set of additive utility functions for multicriteria decision making: the UTA method. European Journal of Operational Research, 10(2), 151-164.

Kabassi, K., Despotis, D.K., Virvou, M. (2005). A multicriteria approach to dynamic reasoning in an intelligent user interface. International Journal of Information Technology \& Decision Making, 4(1), 21-34.

Kanapeckiene, L., Kaklauskas, A. , Zavadskas, E.K., Raslanas, S. (2011). Method and system for multi-attribute market value assessment in analysis of construction and retrofit projects. Expert Systems with Applications, 38(11), 14196-14207.

Liesio, J. , Mild, P., Salo, A. (2007). Preference programming for robust portfolio modeling and project selection. European Journal of Operational Research, 181, 1488-1505.

Liesio, J. , Mild, P., Salo, A. (2008). Robust portfolio modeling with incomplete cost information and project interdependencies. European Journal of Operational Research, 190, 679-695.

Monat, J.P. (2009). The benefits of global scaling in multi-criteria decision analysis Judgment and Decision Making, 4(6) 492-508.

Nemura, A., Klementavicius, A. (2008). Multi-criterion assessment of preferences for communication alternatives of wind power park information system. Informatica, 19(1), 63-80.

Osgood, C.E., Suci, G., Tannenbaum, P.H. (1957). The Measurement of Meaning. Univ. of Ilinois Press, Chicago.

Ouerdane, W., Dimopoulos, Y., Liapis, K., Moraitis, P. (2011). Towards automating decision aiding through argumentation. Journal of Multi-Criteria Decision Analysis, 18(5-6), 289-309.

Ramík, J., Perzina, R. (2010). A method for solving fuzzy multicriteria decision problems with dependent criteria. Fuzzy Optimization and Decision Making, 9(2), 123-141.

Roy, B., Bouyssou, D. (1993). Aide Multicritère a la Decision: Méthodes et Cas, Edition Economica, Paris (in French).

Saaty, T. (1980). The Analytic Hierarchical Process: Planning, Priority, Resource Allocation. McGraw-Hill, New York.

Saaty, T. (2005). Theory and Applications of the Analytic Network Process: Decision Making with Benefits, Opportunities, Costs, and Risks. RWS Publications.

Simon, H.A. (1997). Administrative Behavior: a study of decision-making processes in administrative organizations, 4th edn. The Free Press.

Steuer, R.E. (1986). Muticriteria Optimization: Theory, Computation, and Application. Wiley, New York.

Stirling, W.C. (2003). Satisficing Games and Decision Making: With Applications to Engineering and Computer Science. Cambridge University Press, Cambridge.

Tchangani, A.P. (2006). SANPEV: a satisficing analytic network process framework for efficiency evaluation of alternatives. Foundations of Computing and Decision Sciences Journal, 31(3-4), 291-319.

Tchangani, A.P. (2009). Evaluation model for multi attributes - multi agents decision making: satisficing game approach. International Journal of Information Technology and Decision Making, 8(1), 73-91. 
Tchangani, A.P. (2010). Considering bipolarity of attributes with regards to objectives in decisions evaluation. Inzinerine Ekonomika - Engineering Economics, 21(5), 475-484.

Tchangani, A.P., Pérès, F. (2010). BOCR framework for decision analysis. In: Pierre, B. and Gheorghe, F.F. (Eds.) Proceedings of 12th IFAC Symposium on Large Scale Complex Systems Theory and Applications, Vol. 9, Part 1. http: / /www. ifac-papersonline.net/.

Turskis, Z., Zavadskas, E.K. (2010). A novel method for multiple criteria analysis: grey additive ratio assessment (ARAS-G) method. Informatica, 21(4), 597-610.

Vaidogas, E.R., Sakenaite, J. (2011). Multi-attribute decision-making in economics of fire protection. Inzinerine Ekonomika-Engineering Economics, 22(3), 262-270.

Vincke, P. (1989). L'aide multicritère à la decision. Editions ULB, Bruxelles (in French).

A.P. Tchangani received ingenieur degree (1995) from Ecole Centrale de Lille, France, an MSc degree (1995) and a PhD degree (1999) from Université des Sciences et Technologies de Lille, France in control and automation. After a post doctoral fellowhip at French South Africa Technical Institute in electronics (Pretoria, South Africa), he join Université Toulouse III - IUT de Tarbes in 2001 where he is currently an associate professor. He hold a research position at Laboratoire Génie de Production (LGP) of Ecole Nationale d'Ingenieurs de Tarbes (ENIT) since 2003. Dr. Tchangani's current research interests are in decision analysis, uncertainty modeling and risk management. A list of his publications is available at http://publicationslist.org/tchangani. Dr. Tchangani is a member of IEEE and MCDM societies.

Y. Bouzarour-Amokrane is currently a PhD student at Engineering Production Laboratory of the Engineering School of Tarbes (ENIT). Her researches revolve around structuring of decision aid process by BOCR (benefit, opportunities, cost and risk) analysis. She obtained a master of science degree in industrial engineering from School of Mines of St. Etienne (EMSE), France, after an engineer diploma obtained at the National Polytechnic School of Algiers, Algeria.

F. Pérès graduated from the ENIT (Ecole Nationale d'Ingenieurs de Tarbes) and obtained a PhD from Bordeaux University. He entered the Ecole Centrale of Paris as an assistant professor where he spent 5 years working in the Industrial Engineering Laboratory. He is currently a full professor at Toulouse University, working at the Laboratoire Genie de Production as leader of the Uncertainty Risk and Decision Group. His research study deals with risk management applied mainly to the design and maintenance strategies of manufactured products. Dr. Peres is author or co-author of about 80 articles. 


\title{
Sprendimụ analizès vertinimo modelis: dvipolis požiūris
}

\author{
Ayeley P. TCHANGANI, Yasmina BOUZAROUR-AMOKRANE, François PÉRÈS
}

Sprendimų analizejje, atliekant vertinimą bei nustatant prioritetus (atrenkant, reitinguojant ar rūšiuojant alternatyvas, veiksmus ar sprendimus), šiuo metu dominuoja trys pagrindiniai požiūriai: vertès metodai (kiekvienai alternatyvai išvedama vertės funkcija ar naudingumo matas, atspindintis jos atitikimą sprendimo tikslui); rangavimo metodai (atliekamas porinis alternatyvu palyginimas pagal kiekvieną požymį ar kriteriju, siekiant nustatyti prioritetus alternatyvu aibeje); ir sprendimo taisyklių metodai (sprendimų taisyklių rinkinys nustatomas iš sprendimų lentelès su galimai trūkstamais duomenimis). Pagal visus šiuos požiūrius, turi būti tenkinamas vienas tikslas bei visos alternatyvos apibūdinamos bendrụ požymių ar kriterijų aibe. Šiame straipsnyje mes vadovaujamès požiūriu, kuris pabrěžia dvipolị požymiu pobūdị tikslų atžvilgiu, kas, mūsų nuomone, yra neatskiriama bet kokios sprendimu analizės problemos dalis. Todèl mes pristatome palaikymo ir atmetimo sąvokas požymių ir tikslų santykiams aprašyti bei vertinimo modelį lošimų teorijos struktūroje, pagrịstą dviejų matų ar indeksų (pasirenkamumo ir atmestinumo) kiekvienai alternatyvai taikymu. Požymio palaikymo ar atmetimo laipsnis, atsižvelgiant ị tikslą, yra nustatomas naudojant žinomus metodus, tokius kaip analitinès hierarchijos procesą (AHP). Šis modelis leidžia alternatyvas aprašyti heterogeniniais rodikliais, o alternatyvų nepalyginamumą apibūdinti remiantis Pareto dèsniu. 